\title{
6. Personal Visual Collecting and Self-Cataloguing
}

\begin{abstract}
Chapter 6 analyzes the growing role of the visual in social media practices in terms of tensions between sharing, impression management and self-cataloging.
\end{abstract}

Keywords: sharing; impression management; self-cataloging

In this section of the book, Visualizing Kinship, we explore the particular role of camera phone practices in kinship and family relationships through its aesthetics of mundane intimacy and co-presence. With the rise of algorithms, automation and movements such as quantified self (QS) and attendant methods of self-tracking (Lupton 2016), the role of documenting one's life through different methods have come to the forefront, many of which involve forms of visualization, especially through camera phone use (Pink and Fors 2017a, 2017b). As Humphreys notes, contemporary digital media practices are increasingly about not just quantifying but qualifying the self through creative data archiving and sharing (2019). However, as we will explore later in the book's last section, Co-futuring Kinship, the ramifications of progressively more datafication in everyday life has yet to be fully realized in terms of digital legacy and digital health.

Against this trend, some are opting out of the politics of sharing digital data and instead focusing on representing the ephemeral (such as Snapchat or non-sharing). In these paradoxical trends, camera phone practices are integral. The differences between sharing as a collective memory and nonsharing as a form of diarization play out across cultural and generational divides. This tension between the archive and ephemeral media is at the core of theories around photography and has been harnessed by social media like Facebook "memories" and Instagram "stories."

Hjorth, L., K. Ohashi, J. Sinanan, H. Horst, S. Pink, F. Kato, B. Zhou, Digital Media Practices in Households: Kinship through Data. Amsterdam: Amsterdam University Press, 2020 DOI 10.5117/9789462989504_CHO6 
In conceptualizing Visualizing Kinship, the entanglements between camera phone apps and geo-tagging practices are key. With the rise of geo-tagging camera phone apps, the role of emplacement becomes pivotal. As Hjorth and Pink (2014) note, time and place are emplaced on images through geotagging - creating a flattening of some dimensions in preference for others. This emplacement of locative media within the image creates particular cartographies for memory for the user and their intimates. Camera phones demonstrate that co-presence is reflected in the rhythm and movements across places, spaces and temporalities. Just like intimacy, presence has always been mediated, if not by technologies, then by gestures, language and memory. For Licoppe $(2004,135)$, mobile technologies "provide a continuous pattern of mediated interactions that combine into "connected relationships," in which the boundaries between absence and presence eventually get blurred". Mobile communication inflects presence on diverse levels in which "the ways absent ones make themselves present have been many" and that "copresent interactions and mediated communication seem woven in a seamless web" (Ibid.).

Within current camera phone trends, a tension between the archival and ephemeral relationship can be found. In much of earlier camera phone practices, people often unintentionally archive, taking and storing images of their everyday lives that they may or may not revisit. For first-generation camera phones, without the instantaneity of the app ecology (known as second-generation), sharing was a considered and deliberate act that took time and energy through sites such as Flickr. As Søren Mørk Petersen (2009) notes, digital photo sharing partakes in the logic of "common banality." For Ilpo Koskinen (2007), camera phones amplify a particular type of banality. Mundane co-present intimacy becomes a key motivator within this first-generation of camera phone sharing.

In second-generation camera phone practices, temporality between the act of taking and reflection on sharing is accelerated. It's easier to share than to not share (van Dijck 2008; Holland 2015). Motivations in and around the photographic act are more fleeting, with many of the affordances of camera phone apps seemingly leaning towards a compulsion to share. Scholars such as van Dijck have highlighted (2007), the logic of sharing is the default function for much of social media. For van Dijck in the Culture of Connectivity, sharing has become the "social verb" (2013). Expanding on this idea further, Nicholas A. Johns argues in Age of Sharing that sharing is central to how we live our lives today-it is not only what we do online but also, a model of economy and therapy (2016). Tracing across these areas Johns highlights how sharing can be understood as part of caring practices and discourses.

Moreover, with default time-stamps and geo-tagging, many camera phone apps like Instagram become intrinsic to the process of narrating everyday 
life. Through these moments we create micronarratives of the everyday, which, in turn, create forms of collective memorialization (van Dijck 2008; Sarvas and Frohlich 2011). Apps like Instagram, with their archival-type affordances, create a type of witnessing. This witnessing can create social bonding at the same time as it socializes certain events and moments to the collective witness.

It is whether there is a compulsion to share and make collective these processes, or to compile as part of a personal narrative and catalogue, which interests us in this chapter. How do motivations around sharing play out in different cultural contexts to different social norms of repository and sociality? And how do tensions between the shared and non-shared - the compulsion to archive or not—reflect existing and emerging patterns around the mobile phone as a tool for sociality and self-cataloguing?

Within the politics of second-generation camera phone practices, the emphasis starts to move towards emplacement-emplacing the temporal, social, spatial or geographic (Hjorth and Pink 2014). And yet these emplacements oscillate between practices towards the archive and, conversely, the ephemeral. This tension can be seen in apps like Snapchat and more recently Instagram's "Story" feature that put the emphasis on the ephemeral media. And so how do these tensions between the archive and ephemeral, collecting and diarization, play out in the three sites? And what role does locative media like time-stamps play in the categorizing of this mundane and intimate media into a type of visualizing kinship?

In this chapter we explore the role of the camera phone not only as a portal for collecting, sharing and diarization, but also as a site for which tensions around memory making and temporality. Through the crosscultural discussion we will consider the ways in which collecting is viewed as both a group activity (i.e. networked and co-present affordances) and individual activity (i.e. diarization and self-cataloguing) and how these practices reflect culturally specific notions of the mundane and intimate. Through outlining specific examples, we demonstrate the ways in which camera phone sharing (and non-sharing) is playing out as part of impression management, co-present intimacy, and diarization.

\section{The Politics of Collecting: Sharing and Non-sharing, Group Archive or Self-catalogue}

Our focus on the act of collecting may point to the issues of emerging rules and conventions among friends and family members, and of individuals' 
attempts to manage their identity within the social relationships. Photo collecting can be understood as a form of talk through which one can present images of self to others, and to oneself (Holland 2015; Kuhn 2010). A smartphone is handy and useful "gear" for documenting mundane life. Given the convenience of taking, sending, and uploading the photos, the use of smartphones may increase one's opportunity to generate what Ken Plummer $(1983,2001)$ called "life documents."

In contemporary digital media contexts, Kato (2005) has repurposed this idea of life documents to make sense of mobile media practices within a sequence of daily events. By transferring photos directly, Instagram, for example, can be understood as a group-shared archive of visual notes. An individual can reflect upon their day by tracing the timeline. Also, because a person's friends' photos are weaved into his/her timeline, they can also learn about how others were doing at the particular moment of that day (Van House 2011; Holland 2015). Moreover, by becoming a tool for "life documents," mobile media like Instagram become part of a process for reflection and also encourage forms of self-reflexivity. The documented moments become sites for analysis and discussion. This, in turn, creates a different relationship to the everyday and vernacular media (Gómez Cruz and Lehmuskallio 2016).

Previous studies on first-generation photo sharing suggest that sharing photos over websites may influence the ways in which we understand each other (Kato and Shimizu 2005). In this study, researchers developed an experimental mobile blogging model (moblog) for pedagogical exploration by students. Set in the first-generation camera phone period (i.e. whereby images were transferred to the computer and then uploaded to the internet), the students deployed the camera phone as a researcher's tool for understanding how the everyday is framed, experienced and visualized. What images were uploaded reflected both upon the individual as well as the group. Students considered how these genres represented the group and also became a way to, in turn, understand themselves; in this way, the camera phone became a tool for reflexivity. At the crossroads of teaching students and researchers about ways in which to analyze the everyday, moblog was a valuable tool, eventually being known as the "mother of social media."

There are also historical instances of such research archives, perhaps the most notable being the Mass Observation (MO) project founded in 1937 by Charles Madge, Tom Harrisson and Humphrey Jennings in which analog cameras were used to document everyday Britain. Through the camera, practices and processes of the everyday could be given new forms of visuality and visibility. In particular, they used the camera to explore the social and cultural dimensions of the working class in emerging urban cultures-an 
area which had previously been given little visibility. In turn, MO provided new models for engaging participants and researchers in dynamic ways, leading to what would be understood as new British social documentary. It also had its critics, most notably those that argued that researchers were aestheticizing the lives of the working class rather than providing some form of intervention.

However, researchers such as Harrisson argued that by giving participants camera they were empowering them in new ways to document their life (Highmore 2002). It is against this backdrop that camera phone and the attendant forms of citizen journalism and affective witnessing needs to be understood. Similar criticisms about the aestheticizing of everyday life through camera phone photography can be found (Jurgenson 2012). Yet understanding these practices can provide profound insight into motivations around sharing (and not sharing) everyday moments, and how these become part of the affective witnessing processes (Reading 2015).

Camera phone practices can be framed as part of broader cultures of collecting, yet in doing so they create a specific relationship between the digital, archive and ephemeral (van Dijck 2008; Van House 2011; Broekhuijsen, ven den Hoven and Markopoulos 2017). While digital photographs tend not to take material photographic form, through the mobile device they take on a type of materiality in terms of not only remediating portable devices like the analogue photo album but also create a type of what Anna Reading calls "wearables." Here the relationship between the body, embodiment and data take on a complex entanglement that has both material and immaterial dimensions, or a kind of digital materiality (Pink, Ardèvol and Lanzeni 2016).

As Geismar argues, one of the powerful properties of digital photography is its ability for co-presence. In Geismar's anthropology of photography in locations such as Vanuatu, she considers the,

... structure, the reception and use of digital images of museum collections where many tensions arise between photographic imaginaries of evidence and indexicality in regard to digital images, and the ways in which the social experience of looking is increasingly understood to be part of the digital image (the hallmark of images embedded within social media which is an increasing part of museum digitization projects). In the conservative context of museum imaging, photography is still a primary reference for the authority of digital visualization. However, the opening up of museum collections to new communities of care and engagement allows us to understand digital images of museum collections within the context of a more affective sociality $(2015,306)$. 
The relationship between informal and formal ways of collecting is being transformed through social media practices, especially camera phone apps. It is not uncommon for museums to now consider how they install works to make them more "Instagramable." The more an installation looks good in a picture, the more the picture is likely to go viral. Outside the museum context, personal modes of collecting reflect particular forms of sociality as they conform to specific forms of collective taste (Broekhuijsen et al. 2017; Watkins, Sellen and Lindley 2015). In this way, camera phone practices as tools for replicating and analyzing taste cultures circulating within groups can provide much insight. Take the sharing of food; while food rituals are global, they are also localized in their practices, as we will see in the following sections. They reinforce notions of what Erving Goffman calls impression management at the same time as they allow new forms of front and back stage to play out.

Instagram, for instance, can be understood as a site for one's face-work (Goffman 1959). The notion of face refers to an image as self-delineated in terms of approved social attributes. Through the act of collecting and sharing a photo, an individual is trying to construct and maintain proper relationships with others (Rose 2012; Watkins et al. 2015). An individual's postings are not only displaying to friends/family members what he/she has seen, but how he/she understands the relationships. On some occasions, users may take and share photos for the sake of connected friends, other than for one's own natural interests (van Dijck 2008; Van House 2011). Decisions on whether or not to make the photo visible to others may also reflect one's understanding about the relationships.

On some occasions, individuals are guided by their own communication strategies in terms of what to make available, to whom, and when (Litt and Hargittai 2014). The act of collecting and sharing may no longer be a simple and instinctive reaction to what we encounter in our mundane experiences. Rather, it became an act of making careful decisions in selecting proper photos to be shared, to appropriate groups of connections, in a right timing (Thudt et al. 2016; Rose 2012). In this regard, the act of collecting and sharing can be understood as a moment at which one understands about oneself and the relationships with others are constantly negotiated (Uimonen 2016; Vivienne and Burgess 2013).

\section{Tokyo}

As aforementioned, in Japan mobile phones are used as a tool to connect with intimates, especially family members (Ito et al. 2005; Matsuda 2005). 
While the mobile phone has a longer history in Japan, smartphones started to become an integral communication tool among family members, not only through their provision of e-mail, SMS, and telephone services, but also as a portal to social media in the late $2000 \mathrm{~s}$.

As Richard Chalfen (2011) notes in his analysis of the "shinrei shashin" (ghosts in snapshots), the relationship between ghosts and photography in Japanese culture challenges conventional readings of the snapshot. Mobile media and especially smartphones further complicate this situation in networked visuality and the attendant forms of affective witnessing (Papailias 2016). While photography has a long and important history in the role of the family and memory at a global level, as Chalfen highlights, this phenomenon is particularly prevalent to Japan (2011).

As discussed in Chapter 2, since 3/11, Tokyo's use of mobile media has gone under serious recalibration. With growing distrust of broadcast media like NHK (after they withheld important information about the Fukushima nuclear disaster), many millions have turned to mobile media like Twitter, Line and Instagram to help negotiate a constant co-presence between friends and family. In particular, according to a Toyokeizai media report, 90\% of Instagram users are under the age of 35 and almost $70 \%$ of its users are female (Toyokeizai online 2014). Instagram has exploded in popularity in Japan since 2014, four years after its inception. Camera phone practices can be understood as a vibrant part of contemporary visual culture. In order to understand the gendered use of Instagram, we introduce three examples that highlight the functions and meanings of camera phone practices as a way in which to navigate the everyday, its rituals and co-present intimacies.

Mari was a 21-year-old Japanese graduate student. She bought a sumaho (smartphone) when she started at university and used LINE, Facebook, Instagram and Twitter. While she used LINE to communicate with her friends and family, Instagram - which she started to use the year before our research — was deployed the most to share photos with her friends. When she had time to spare, she opened Instagram and checked her friends' photos. As Mari described, "I share photos on Instagram to save my favorite moments and daily things. It's a kind of diary. Whenever I travel, I share photos on Instagram." She shared travel photos with location information and there were many photos of food and scenery on her Instagram. Instagram had effectively replaced Twitter and Facebook, which she had not updated for some time.

Mari was aware of her followers when she shared photos on Instagram. She didn't share photos if she thought that they were not interesting for her 


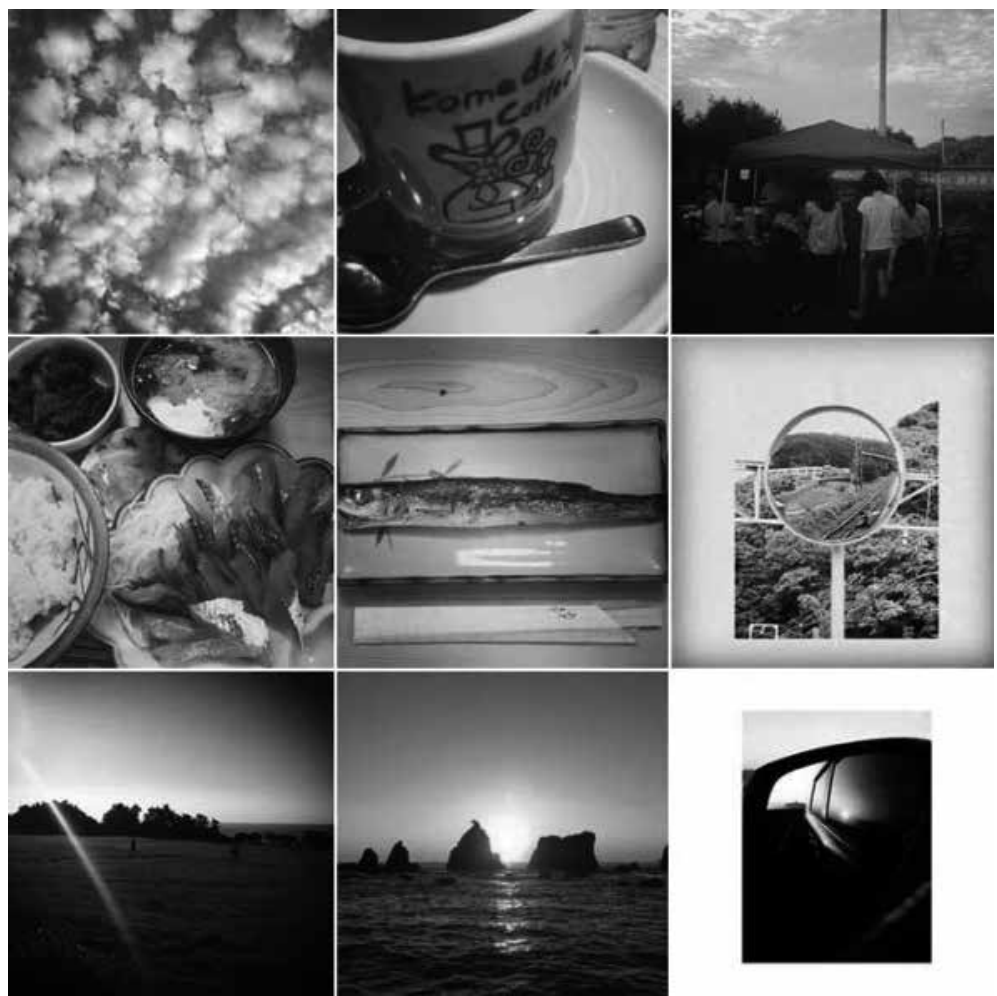

Figure 6.1: Mari's Instagram images

followers. For Mari the choice of what to share and what not to share involved maintaining a sense of intimacy through the mundane. As Mari notes:

On Facebook, there are too many 'friends' who are not my real friends. But on Instagram, most of the followers are my real friends. I would like to share my interesting experiences with them using Instagram. On Instagram you can show them what you saw and experienced.

Nozomi was a 22-year-old graduate student who started to use sumaho when she was a high school student. She used Instagram and LINE on sumaho. She had Twitter and Facebook accounts, but had not used them for a year. Although she had been an active user of Twitter and had more than 1200 followers, on seeing unpleasant tweets from her ex-boyfriend, she deleted the Twitter app. She found Facebook boring because people post only "official reports" on it. She used LINE, a Japanese social network site, to communicate with friends and family. 


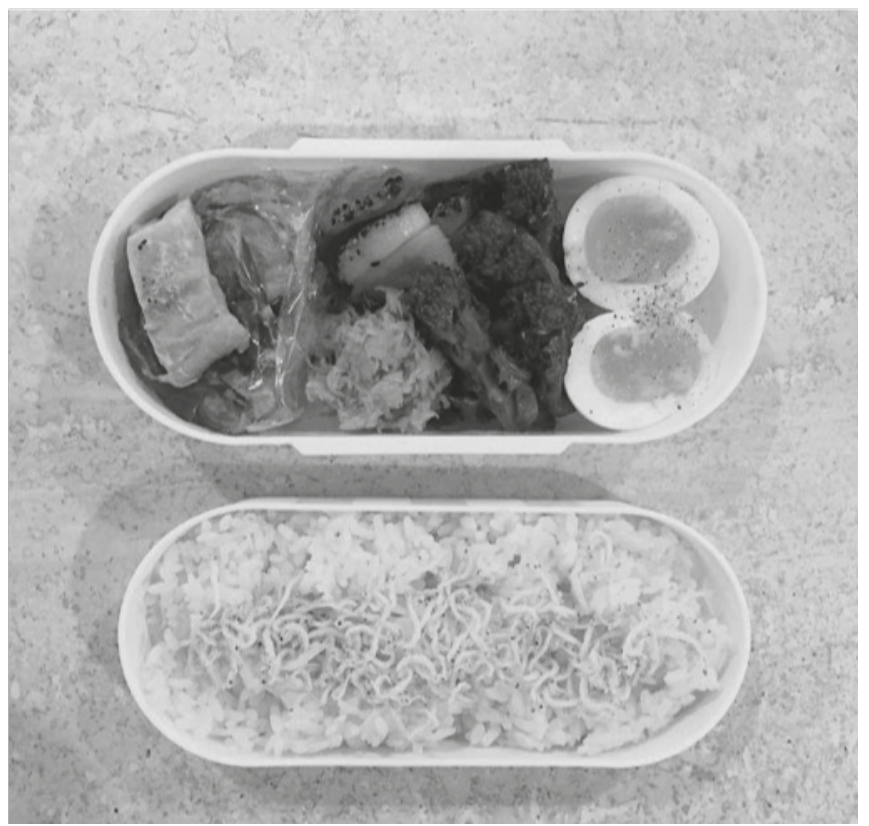

Figure 6.2: Nozomi's lunch photographed and shared

When it came to sharing photos, she used Instagram the most. She started to use it because of its editing features. "I was surprised. My photos became so cute with this. Then I started to use it." She shared photos almost on a daily basis. When she traveled, the number of photos posted increased. She opened Instagram five or six times a day. She not only followed her friends, but also celebrities. "I enjoy watching private life of celebrities. I enjoy my friends' photos and check in which restaurants they had lunch/dinner. Also, I learn how to take a good photo." Nozomi also shared photos of food and interesting things she found in her everyday life and travels. She often shared photos of fancy food in restaurants/cafes, and also bento (lunch box in Japanese) and dishes she made.

Sometimes Nozomi did not share photos even though she had fancy food in a good restaurant. "When I share photos of fancy food on Instagram, I'd like to make my friends jealous. But I am careful not to do it too much." The photos of bento and dishes she made were taken and shared mainly for the record, but she "styled" the food so that it looked nice. She often enjoyed looking at the old photos on Instagram. “I can't imagine my life without Instagram. Good memories and my daily things are on it. It reminds me of what I have done with visual images." Nozomi's use of Instagram was dual functional - a tool for self-diarization while also performing the mundane 
for friends. While the images were of everyday situations like food, they were presented in a highly stylized way. Here Instagram allowed her to transform the mundane into a spectacle.

21-year-old graduate student, Rina, bought a sumaho when she started university. She used LINE, Twitter, Facebook, Instagram and Snapchat. For photo sharing, she used Instagram the most, which she started to use for its editing features. Rina used to use Facebook for photo sharing, but she got tired of it. "I'm full. There are too many friends on Facebook and I'm tired of watching photos of their life events." Her Instagram account was private, and Rina was trying to limit her followers to 100, so sometimes she declined requests from friends who were not close. As she noted:

Instagram is the most 'homely' social media for me. On each social media, my degrees of self-disclosure are different. For example, on Facebook $20 \%$, on Twitter $30 \%$ and on Instagram more than $70 \%$. About LINE and Snapchat, I use them to communicate with only familiar people.

Rina shared photos once a week, when she wanted to express something or to keep records. Recently she had enjoyed visiting beef barbecue restaurants and when she visited a new restaurant, she shared photos with location information. Here we see Rina using Instagram to package the mundane as informative so that her friends might learn of different restaurants. Through these snapshots of the mundane Rina highlighted difference and similarity between herself and her friends.

For our Tokyo participants, one of the biggest motivations for sharing photos was to attract their friends' interest and reinforce the significance of their co-present in everyday life. To accomplish this purpose, respondents carefully took, selected, edited and shared photos of their everyday life. Being both mundane and intimate in content and context, the pictures sought to create an ambience of being there. The participants cared about their friends' reaction to their photos. They checked the number of "Likes" and comments, and also talked about the photos when they met with friends. Those photos were very important tools for their "impression management," evocative of Goffman's (1959) work around presentations of self in everyday life. The collection of the photos on Instagram represented not only their everyday experiences but also how they wished to tell their everyday experiences and wanted to be seen (Holland 2015; van Dijck 2008).

Some of our participants connected with their sibling/s and/or wife/ husband, but none of them connected with their parent/s on Instagram. The "impression management" to be seen "cool" is directed towards mainly 
close friends and family members of the same generation. Here we see that through Instagram they created intimate publics that can differentiate between sharing with family and friends (Holland 2015; Vivienne and Burgess 2013). Many of the participants used Instagram in combination with social media LINE to compartmentalize what their parents see and don't see. Respondents used LINE, rather than Instagram, to share photos with their parent/s.

The collection of photos on Instagram was not only important for keeping in constant contact with friends but also for their self-satisfaction. Also, an act of selecting 'proper' photos for sharing can be understood as a reflection of one's desire to be recognized and approved by other members of the community (Van House 2011; Watkins et al. 2015). By carefully maintaining one's images to be shown/not shown, he/she manages to situate him/herself within the social relationships (Uimonen 2016; Litt and Hargittai 2014). When they got tired in everyday life, they recalled pleasant moments "to feel happy" by scrolling the feed on Instagram. And they rediscovered their friends' comments and the number and name list of the "Like" button. Once they shared photos on Instagram, the photos became something more meaningful in conjunction with their friends' reactions (van Dijck 2008; Sarvas and Frohlich 2011).

\section{Melbourne}

Smartphones with locative technologies are relatively pervasive in Australia, and this rate of pervasiveness is increasing rapidly. Smartphone penetration in Australia was $37 \%$ at the beginning of 2011 ; two years later, at the beginning of 2013, that figure had risen to 65\% (Our Mobile Planet 2013; ACMA 2013). But unlike Tokyo, which already has a decade of mobile internet, Melbourne is relatively new to the phenomenon. Other recent research has indicated that the number of people who own either a smartphone or a tablet has risen to over $70 \%$ in this Australian city (Deepend 2014). Device penetration is relatively high across most age demographics. Within certain age brackets, such as the $25^{-29}$ demographic, ownership of smart devices is over 9o\%; however, even older demographics, such as the over-6os, report smart phone ownership of $55 \%$ (Ibid.).

Unlike Japan's highly gendered use of Instagram, Australia has about $60 \%$ women and $70 \%$ of total users are between the ages of 18 and 34 . In recent statistics released on social media usage, Instagram has 5 million monthly active Australian users, which represents a $30 \%$ growth in the last 12 months and implies that around $21 \%$ of the Australian population own 
an Instagram account (Social Media News 2015). Australians follow these main interests: friends (61\%), photography (40\%) and travel (40\%). These dominant genres were echoed in our fieldwork in Melbourne. Just as the genres and demographics are similar to Tokyo, the way in which Instagram is used to rediscover the poetics of the mundane and the everyday can also be paralleled between the two sites.

22-year-old Yana lived in the outer suburbs of Melbourne with her partner 28 year-old Nathan and her young son. She was a keen user of Facebook, Instagram and Pinterest, but she only considered Facebook as being "social," and somewhere she would actively seek to have a conversation with her friends or have a look at what they were doing. She considered Instagram and Pinterest to be personal entertainment, where she chose to only browse images. As Yana described Instagram, "For me, it's not a social thing, it's just for me."

When we visited Yana in her home, it was clear that she lived in a family of collectors. Nathan had a cabinet full of Star Wars and Call of Duty figurines, models and Lego that he made and displayed, and her son uses the dining table as a space where he built his own Lego displays. "Collecting" gives us some further clues to how Yana thought about social media, as prior to using Pinterest and Instagram she was an avid subscriber of Fashion Trends Forecast magazines. Yana reflected:

I paid for forecasting magazines and they're not cheap and I think that this (Pinterest and Instagram) is more relevant than a forecasting magazine because a forecasting magazine is only really seen by people in the industry, whereas, this is seen by everybody and I think this is more valuable than a forecasting magazine just quietly.

Yana still kept her magazines stacked in piles in her study. "It hurts me to throw them away, so I've started recycling them and using them for things and chopping them up. For gift wrapping paper and stuff." Yana's study was connected to her kitchen by a long corridor and she had decorated the walls with collages of photos hung in frames. She printed the photos from her phone and digital cameras before she owned her smartphone. "They're all from the phone. Just family stuff, that's just fun that you don't really want on social media, but I've got one up there I'm in a bikini, that's not going on Facebook but I'm happy to have it in my house sort of thing." Yana also kept boxes of printed photos with her magazines in the study.

In addition to her photos and magazines, Yana also had a collection of recipe books in a cabinet in her kitchen. She would look up recipes 
online and save them, although she pointed out that she also still used recipe books as well as online sources to inspire her. Although Yana's use of Instagram and Pinterest was less of a diary than those of the examples of our participants from Tokyo, her use of these platforms was still highly personal as they represent private collections that she used similar to the way she previously related to print media (Thudt et al. 2016; Watkins et al. 2015).

Family meals and food preparation have always been an important part of Lily's home life. Before she was married and still lived at home with her parents, enjoying her mother's meals with her siblings was a part of their shared experiences growing up. During one of our research visits, Lily had a bookshelf in her kitchen where she kept scrapbooks, exercise books and display folders of recipes she had collected over the years, along with recipe books she had bought or had been given. As Lily reflected:

This is like my old folders; this is all my sweets, that's all my savories, so sweets a lot thicker, but I don't use all of these recipes so I was finding I really had to go through, and what I was planning to do was go through and either make notes or throw out the ones that I don't use. So, cheesecakes, I might have two recipes; if this one's better I want to keep one and chuck the other, but I've never gotten round to it. So there's heaps in here, and there's some I will keep coming back to and others I haven't used since I've printed them out. So they do need a good sort through.

Lily had downloaded the Paprika app on her phone, which allowed her to browse recipes and save them to her own lists, just like "lunches" or "baking." Lily reflects:

I do still like print copies, so I do have recipes books, I do have booklets of recipes as well. But Paprika is pretty good as well because it's all there and you can have your own categories, desserts, mains, whatever you want. You can tag them anyway and so it's sorted there.

Lily also took photos of the dishes she prepared, mostly baking and shared them over WhatsApp with a few of her friends, a couple who were also young mothers who she exchanged meal planning ideas with and another who enjoyed baking. "Generally, the finished product, but because it's been baking breads and scrolls and stuff then it could be in the middle when it's proving; 'How does this look? Is it almost there?' If someone just wants tips or something." She kept some of the photos if the dish looked 
exceptionally good or if it was a good photo, but she deleted most of the photos.

Collecting recipes and exchanging meal ideas with her friends also allowed her to bond with her mother. As Lily noted:

She's a good cook so she's got lots of good stuff that I enjoy, so these are the key ones and I'm like, "Can you please just write that down before we lose you" or whatever, you know what I mean. Because she cooks by feel she doesn't really have recipes, so she was trying to capture all that for me. So yes, there's a few but they're really old, you can see. Some are just her dictating, "This is what I'm doing" so I'm trying to scribble it down. And it's never accurate because she'll taste and she'll add a bit of this, a bit of that.

Recipe browsing and curating websites and apps had complimented her hard copy collection of recipes. Lily continued:

Everything now is so much easier on the net, so it's easier to sometimes go to your Safari and look up a recipe. Taste has heaps and there's good ones there too. The ones that I know are good I've started trying to put into Paprika, or ones that I want to try, and then over there it's easy, you can make notes as well. If you've tried it once and it's too salty maybe come down in salt, so I'll make a little note in there.

In Melbourne, taking and retaining images as archiving can be better understood in relation to habits of collecting prior to social media. In the cases of Yana and Lily presented below, collecting was experienced as a private past time. Before discovering Pinterest, Yana was an avid collector of magazines and Lily has an extensive collection of recipes, both in the forms of "old media" from hand-written notes from her mother and magazine clippings and "new media," where she has downloaded a couple of apps for collecting and curating recipes.

Further, food and food preparation were an important part of Lily's family and social life. When she had baked a dish for example, she would share a photo of the finished product with her friends over WhatsApp. Lily did not intend to keep or archive her images; rather, they were a type of visual conversation with her friends at that time (van Dijck 2008; Holland 2015). By contrast, Yana's husband Nathan was a professional chef. She often took photos of food he had prepared for the family, but she never displayed them digitally, but only showed them to her friends in conversation. 


\section{Shanghai}

Photo sharing is a common phenomenon on Chinese social media such as WeChat. The history of the camera phone practice can be dated back to the social networking website Qzone and different online photo albums in the 20oos. Unlike Melbourne and Tokyo, due to the Great Firewall (GFW, the Chinese governmental block practice for certain foreign websites, including Google, Facebook and Twitter), Chinese users have not had access to internationally popular photo sharing platforms like Instagram unless they used special ways to leap over the GFW. In the past decade, the popular platform for personal photo sharing has drifted from Qzone to Renren. com/ Kaixin.com to Weibo, paralleling the development of the internet in China. However, as WeChat got a huge number of monthly active users (549 million in 2015 Q1) (Tencent 2016), WeChat has gradually taken first place in personal photo sharing in China.

Within WeChat, users can not only take photos but also share them, either directly to certain friends or in WeChat Moments. The camera function built in WeChat Chats allows users to take and share photos at any given moment whilst in dialogue with others. The photo sharing function in Moments is designed as the basic social function. As pictures give more vivid information and draw more attention, the photo sharing function has successfully enhanced the social attribute of WeChat and has led to a new fashion within the Chinese social media arena.

Graduate student Tiffany moved to Shanghai from a southeastern coastal city called Xiamen. Being apart from her parents, Tiffany usually shared her life with her family via WeChat. She had created a family WeChat group that included her parents and herself. The family enjoyed sharing photos, especially photos of food, in the WeChat group.

In the screenshot above, Tiffany (on the right) shared a photo of dumplings from the school canteen to their family WeChat group at lunchtime, indicating the everyday event that she had had dumplings for lunch that day. Seeing the photo, her father replied with texts that he also had dumplings for lunch. This conversation over WeChat can be regarded an epitome of typical daily family communication on WeChat.

In addition to sharing photos of her life events with her parents, Tiffany enjoyed sharing photos in Moments. However, when she was doing photo sharing in Moments, she was cautious about the quality of the photo and the wording of illustration. "Photos you share speak for your taste and style. I want to be an interesting person and want to be regarded as an interesting one." 


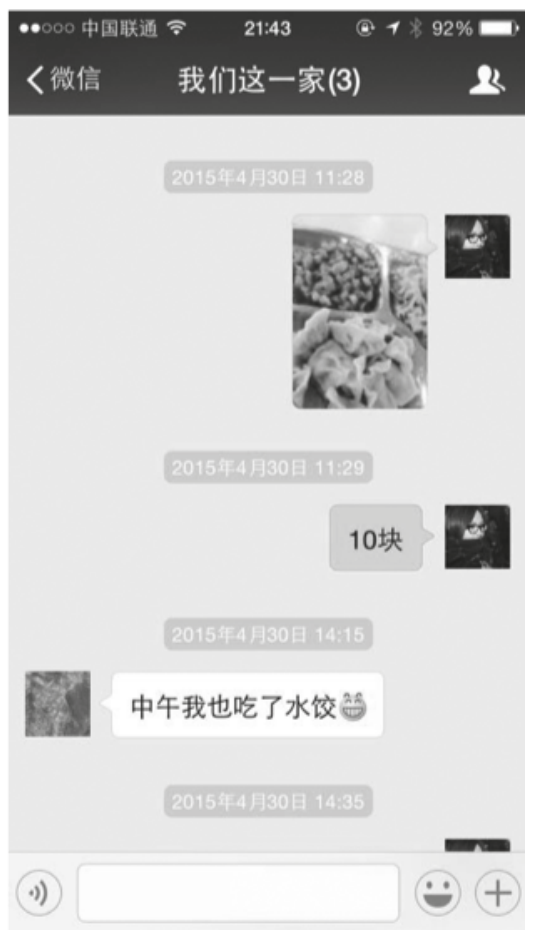

Figure 6.3: Tiffany sharing a photo of her school dumplings with her family

Tiffany posted nine photos after her trip from New York. She drew a parallel between photos of landmarks in NYC taken by her own mobile phone and landmarks on postcards. This fantastic idea won her a large number of "likes" on WeChat.

Ben was a graduate student of landscape design in Hannover, Germany. He was born and grew up in Shanghai. After finishing his undergraduate study in a university in Shanghai, he applied for a master's program in Germany to pursue his dream as a professional designer. Ben likes photography and was a guru in Photoshop.

Ben viewed the sharing of photos as a gendered preoccupation and did not share as many as his female counterparts. Instead, he shared photos occasionally. Notably, he would only share photoshopped photos of trips that he had been on, saying that. "When I go on a trip and I take some nice photos, I want to keep a record and to mark the unique experience. So sometimes I would share my photos in Moments when I am in that mood. Also, I feel better with processed photos instead of the original one." 
Wo ist Wochenende? Keine Ahnung. Immer unterwegs
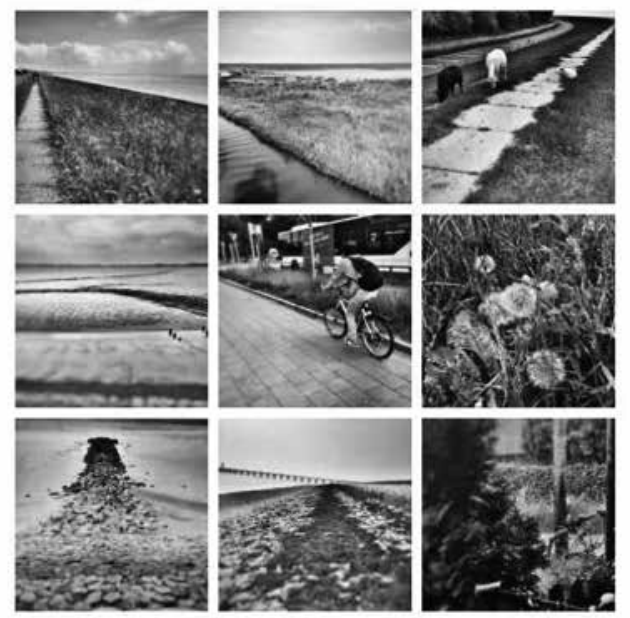

8 day(s) ago

Figure 6.4: Post by Ben

The role of photo sharing as an extended form of collecting continued to play an important part in each of the locations. Specifically, its role in managing relationships, co-presence and intimacy was significant. Participants spoke about having certain family or friends in mind when they posted something and using a variety of platforms to "select" specific contexts, meanings and audiences. In each of the multiple platforms of the participants, there were particular groups of intimates that then shaped what they shared and when they shared. The tension between digital archiving/ legacy/collections and ephemeral moments was apparent in the different usage from Snapchat to Instagram to WeChat.

As evidenced in the examples discussed in this chapter from three cities, younger generation users (mostly in the Tokyo and Shanghai cases) tended to use social media for displaying their day-to-day mundane, and as a form of "impression management." While they were careful enough not to make their friends "too jealous," the photos shared and the act of sharing itself were still playing an important role in displaying how they are organizing their everyday mundane experiences.

In part, cultural differences may become salient, with regard to the ways in which individuals present themselves to others. For these participants 
sharing photos was a form of communicating and expressing their tastes and lifestyles. In contrast, young mothers (in the Melbourne examples) were focused on the relationships within their family members and/or intimate friends and acquaintances. Rather than presenting tastes and lifestyles to a broader audience, their interests are geared toward sharing and nurturing memories within a confined group of people.

As demonstrated in this chapter, food is a popular subject to be captured and shared over SNS in the present cases. In fact, this tendency may be found across many other cultures as well. Whereas cases in Melbourne suggest that food photos are mainly for one's personal collection (also for practical reasons), cases in Tokyo and Shanghai illustrate that the SNSs play an important role as a site for demonstrating their eating and/or cooking behaviors. It also creates a site for constructing role images of housewives, or of female in general.

For example, in May 2015, the official Twitter account of the Cabinet Secretariat of Japan uploaded a photo of a bento box. There, a photo of kyaraben (a bento decorated to look like characters from anime) prepared for kids was shown, accompanied with texts depicting that the bento box is a symbol for a hard-working and caring mother. The page itself was titled as "For an encouragement of female (in Japan)" and was linked to a web page of a popular "charismatic" housewife who uploads kyaraben photos almost every day. Immediately after the tweet, the site was "flamed" with many complaints and oppositions to the idea of promoting such an image through bento photos.

The claims were that it was unrealistic for an ordinary working mother to spend that amount of time and energy on preparing bento boxes, and thus the image depicted was far from the "real" mundane social experience. This controversy shows how mundane social media photos can be taken out of context from a personal to a public realm. This instance highlights that while we might think we have control over the shaping of our intimate publics that are social mobile media, there are still many areas—especially in terms of digital legacy — that we are still to fully comprehend (van Dijck 2008; Holland 2015).

The ideas of sharing as a collective memory and non-sharing as a form of diarization may coexist balanced by both cross-cultural and culturally specific contexts (Uimonen 2016; Litt and Hargittai 2014). In part, such balance can be understood in terms of cultural differences, where users in Tokyo (and Shanghai) tend to use photos to present themselves for circulation purposes, with understandings that photos on social media may reflect socially desirable images of individuals. 
Occasionally, they acknowledge peer pressures to conform to certain tastes and lifestyles due to a relatively homogeneous culture. Still other parts can be understood in terms of participants' age (life stage) and their experiences with social media. Though there are cross-cultural differences, a focus on the act of collecting and sharing may be an entry point to speculate upon our images and understandings about role expectations (e.g. gender roles) within a society (Rose 2012; Holland 2015). In the next chapter we continue the focus on visual kinship to reflect how the visual genres play a role in how kinship is maintained, managed and mitigated.

\section{Conclusion: Sharing and Non-sharing}

Much of the literature into mobile visuality-especially in terms of camera phones - speaks about the important role of sharing as part of its logic (Frohlich et al. 2002; Kindberg et al. 2005; Van House et al. 2005; Koskinen 2007; van Dijck 2013). Indeed, as noted earlier, sharing has become a form of logic for contemporary cultural practice (Johns 2017). However, against this logic of sharing and co-presence emerge other, less articulated practices-most notably, the act of mobile visuality as a non-shared artefact. While previous research tends to pay attention to the social role of mobile media as a tool for communicating, socializing and accessing internet, we focus upon the internalized practices of mobile visuality as a non-shared activity that plays into different notions of memory making and cataloguing of the self.

As we found at the end of the study, many participants came to talk about non- sharing as a form of memory making. Against the compulsion of the digital archive that much of camera phone practices have contributed to, ephemeral apps like Snapchat and practices such as non-sharing (i.e. keeping the photo on the phone just for personal, individual use, started to emerge. This phenomenon seems to suggest participants are finding ways in which to resist the data trails and the default settings of locative media, which "emplace" place and time in the framing of the photo app geo-tag (Hjorth and Pink 2014). As algorithms and big data create anxieties around privacy, the option and right to not share will become more prevalent (boyd and Crawford 2011).

Moreover, with the rise in "spontaneous" and ephemeral media like Snapchat there is increasingly a need for researchers to think about mobile visuality beyond the archive. This non-sharing component of mobile visuality is about different forms of intimacy, memory and emplacement (Thudt et 
al. 2016; Uimonen 2016). In turn, this requires us to develop new methods that understand this non-sharing practice as part of nuanced reading of everyday life (Litt and Hargittai 2014). However, as we explore in the next chapter, sharing is still very much a way of curating co-present sociality and intimacy while emplacing locative media.

\section{References}

ACMA. 2013. "Communication Report." http://www.acma.gov.au/theACMA/Library/ Corporate-library/Corporate- publications/communications-report. Accessed 20 May 2015.

boyd danah, and Kate Crawford. 2012. "CRITICAL QUESTIONS FOR BIG DATA: Provocations for a cultural, technological, and scholarly phenomenon." Information, Communication and Society 15 (5): 662-679. DOI: 10.1080/1369118X.2012.678878.

Broekhuijsen, Mendel, Elise ven den Hoven, and Panos Markopoulos. 2017. "From PhotoWork to PhotoUse: Exploring personal digital photo activities." Behaviour and Information Technology 36 (7): 754-767. DOI: 10.1080/0144929X.2017.1288266.

Chalfen, Richard. 2011. "Doing family photography: The domestic, the public and the politics of sentiment." Visual Studies 26 (2): 176-178. DOI: 10.10 8o/1472586X.2011.571905.

Deepend. 2014. "Making digital work harder: Australian mobile device ownership and homeusage report 2014." http://www.deepend.com.au/download-whitepaper-device-usage-in-the-home. Accessed 20 May 2015.

Frohlich, David, Allan Kuchinsky, Celine Pering, Abbe Don, Steven Ariss. 2002. "Requirements of photoware." Proceedings of the 2002 ACM conference on Computer supported cooperative work, New Orleans.

Geismar, Haidy. 2015. "Post-photographic presences, or How to wear a digital cloak." Photographies 8 (3): 305-321. DOI: 10.1080/17540763.2015.110276o.

Goffman, Erving. 1959. The Presentation of Self in Everyday Life. New York: Random House.

Gómez Cruz, Edgar, and Asko Lehmuskallio. 2016. Digital photography and everyday life: Empirical studies on material visual practices. New York: Routledge.

Highmore, Ben. 2002. Everyday Life and Cultural Theory. London: Routledge.

Hjorth, Larissa, and Sarah Pink. 2014. "New visualities and the digital wayfarer: Reconceptualizing camera phone photography and locative media." Mobile Media \& Communication 2 (1): 40-57. DOI: 10.1177/2050157913505257.

Holland, Patricia. 2015. "'Sweet it is to scan...': personal photographs and popular photography." Photography: A Critical Introduction, edited by Liz Wells. 133-188. Abingdon; Oxon: Routledge. 
Hogan, Bernie. 2010. "The presentation of self in the age of social media: Distinguishing performances and exhibitions online." Bulletin of Science, Technology and Society 30 (6): 377-386. DOI: $10.1177 / 0270467610385893$.

Institute for Information and Communications Policy. 2014. "Heisei 25 nen jouhou tsushin media no riyou jikan to jouhou koudou ni kansuru chousa sokuhou (The results of a survey of the utilization time of telecommunication media and information behavior)." http://www.soumu.go.jp/iicp/chousakenkyu/ data/research/survey/telecom/201 4/h25mediariyou_1sokuhou.pdf. Accessed 30 June 2014.

Ito, Mizuko, Misa Matsuda, and Daisuke Okabe. eds. 2005. Personal, portable, pedestrian: Mobile phones in Japanese Life. Cambridge: The MIT Press.

Johns, N.A (2016) The Age of Sharing. New York: Wiley.

Jurgenson, Nathan. 2011. “The Faux-Vintage Photo.” The Society Pages. http:// thesocietypages.org/cyborgology/2011/05/14/the-faux-vintage-photo- full-essayparts-i-ii-and-iii/. Accessed 20 May 2015.

Kato, Fumitoshi, and Aiko Shimizu. 2005. "Moblogging as face-work: Sharing a "community-moblog" among project members." A position paper submitted to PICS Workshop (Pervasive Image Capture and Sharing: New Social Practices and Implications for Technology), UbiComp2005, September 11, Tokyo, Japan.

Kindberg, Tim, Mirjana Spasojevic, Rowanne Fleck, and Abigail Sellen. 2005. "The Ubiquitous Camera: An In-Depth Study of Camera Phone Use." IEEE Pervasive Computing 4 (2): 42-50. DOI: 10.1109/MPRV.2005.42.

Koskinen, Ilpo. 2007. "Managing banality in mobile multimedia." In The Social Construction and Usage of Communication Technologies: European and Asian Experiences, edited by Raul Pertierra, 48-6o. Singapore: Singapore University Press.

Kuhn, Annette. 2010. "Memory texts and memory work: Performances of memory in and with visual media." Memory Studies 3 (4): 298-313. DOI: 0.1177 / 1750698010370034 .

Licoppe, Christian. 2004 “'Connected' presence: The emergence of a new repertoire for managing social relationships in a changing communication technoscape." Environment and Planning Design: Society and Space 22 (1): 135-156.

Litt, Eden, and Eszter Hargittai. 2014. "Smile, snap, and share? A nuanced approach to privacy and online photo-sharing." Poetics 42: 1-21. DOI: 10.1016/ j.poetic.2013.10.00.2.

Lupton, Deborah. 2016. The Quantified Self: A Sociology ofSelf-Tracking. Cambridge: Polity Press.

Matsuda, Misa 2005. "Discourses of the keitai in Japan." Personal, Portable, Pedestrian: Mobile Phones in Japanese Life, edited by Ito, Mizuko, Daisuke Okabe, and Misa Matsuda. 19-39. Cambridge: The MIT Press. 
Mørk Petersen, Søren. 2009. "Common banality: The affective character of photo sharing, everyday life and produsage cultures." PhD diss., IT University of Copenhagen.

Our Mobile Planet. 2012. "Our Mobile Planet." http://www.thinkwithgoogle.com/ mobileplanet/en/. Accessed 21 May 2016.

Papailias, Penelope. 2016. "Witnessing in the age of the database: Viral memorials, affective publics, and the assemblage of mourning." Memory Studies 9 (4): 437-454. DOI: 10.1177/1750698015622058.

Pink, Sarah, Elisenda Ardèvol and Dèbora Lanzeni. 2016. Digital Materialities. London: Bloomsbury.

Pink, Sarah, and Vaike Fors. 2017a. "Being in a mediated world:Self-tracking and the mind-body-environment." Cultural Geographies. Online first. DOI: 10.1177/1474474016684127.

-2017b. Self-tracking and mobile media: New digital materialities." Mobile Media and Communication. Online first. DOI: 10.1177/2050157917695578.

Plummer, Kenneth. 1983. Documents of Life: An introduction to the problems and literature of a humanistic method. London; Boston: Allen \& Unwin.

-2001. Documents of life 2: An invitation to a critical humanism. London: Sage.

Reading, Anna. 2016. Gender and Memory in the Globital Age. Basingstoke: Palgrave.

Rose, Gillian. 2012. Doing family photography: The domestic, the public and the politics of sentiment. Kent, UK: Ashgate Publishing Ltd.

Sarvas, Risto, and David M. Frohlich. 2011. From snapshots to social media - The changing picture of domestic photography. London: Springer-Verlag.

Social Media News. 2016. "Social Media Statistics - August 2015." www.socialmedianews.com.au/social-media-statistics-australia-august-2015/. Accessed 21 May 2016.

Tencent. 2016. “2016 Annual Report.” http://www.tencent.com/zh-cn/content/ir/ rp/2016/attachments/201601.pdf (In Chinese). Accessed 1o February 2017.

Toyokeizai online. 2014. Toyokeizai online. http://toyokeizai.net/. Accessed 21 May 2016.

Thudt, Alice, Dominikus Baur, Samuel Huron, S., and Sheelagh Carpendale. 2016. "Visual Mementos: Reflecting Memories with Personal Data." IEEE Transactions on Visualization and Computer Graphics 22 (1): 369-378.

Uimonen, Paula. 2016. “I'm a picture girl.' Mobile photography in Tanzania.” In Digital photography and everyday life: Empirical studies on material visual practices, edited by Edgar Gómez Cruz and Asko Lehmuskallio, 19-34. New York: Routledge.

van Dijck, José. 2008. “Digital photography: communication, identity, memory.” Visual Communication 7 (1):57-76. DOI: 0.1177/1470357207084865.

—.2013. Culture of Connectivity. Oxford: Oxford University Press. 
Van House, Nancy A. 2011. "Personal photography, digital technologies and the uses of the visual." Visual Studies 26 (2):125-134. DOI: 10.1080/1472586X.2011.571888. Vivienne, Sonja, and Jean Burgess. 2013. "The remediation of the personal photograph and the politics of self-representation in digital storytelling." Journal of Material Culture 18 (3): 279-298. DOI: 10.1177/1359183513492080.

Watkins, Rebecca. D., Abigail Sellen, and Siân E. Lindley. 2015. "Digital collections and digital collecting practices." Proceedings of the 33rd Annual ACM Conference on Human Factors in Computing Systems, 3423-3432. 
